\title{
Roles, Risks, and Benefits of Peer Mentoring Relationships in Higher Education
}

\author{
Janet W. Colvin and Marinda Ashman \\ Utah Valley University
}

\begin{abstract}
Successful peer mentoring in university settings is the result of relationships among students, mentors, and instructors. Findings from this study indicate that even in programs where training is ongoing and established, assumptions cannot be made about the understanding of the roles, risks, and benefits involved in such relationships. This study demonstrates that students, instructors, and mentors all have different perspectives about a mentor's role and how that role should be enacted. Connecting link, peer leader, learning coach, student advocate, and trusted friend were identified as predominant roles enacted by mentors. Also described are risks and benefits for being or having a peer mentor.
\end{abstract}

Keywords: peer mentor, roles, risks, benefits

In higher education, teaching takes place in different ways. Instructors, highly trained in their area of expertise, engage students through technology, lecture, service learning projects, experiential activities, and more. Teaching also occurs between and among students as they work together and at times mentor each other in and outside the classroom. Though instructors may wish otherwise, this sort of peer teaching may have an even greater impact on students than teaching in the classroom (Goodlad, 1998).

Because peers have such an impact on one another, over the years there have been many attempts to harness and utilize this influence more formally. Undergraduate students on college and university campuses have been assisting peers academically since the 1700s (Materniak, 1984). Peer educators now often act as counselors and advisors and also provide training when previous experience lends itself to facilitating learning.

Universities are increasingly seeking alternative approaches to education that supplement traditional classroom learning, especially given that budgets have been cut and student populations have risen in many universities (Miller, Groccia, \& Miller, 2001). Some universities are turning to learning communities (e.g., LaFee, 2003; Miller, 2000; Smith, 1993), and others are using peers to enhance learning in online classrooms (e.g., Bierema \& Merriam, 2002; Campbell \& Campbell, 1997; Dyrli \& Kinnaman, 1995; Grant-Vallone \& Ensher, 2000; Kazmer, 2004). Still others are implementing peer programs to help students transition to college and/or

Janet W. Colvin, Department of Communication, Utah Valley University; Marinda Ashman, Department of College Success Studies, Utah Valley University.

Correspondence concerning this article should be addressed to Janet W. Colvin, Department of Communication, Utah Valley University, 800 W. University Parkway, LC240, Orem, Utah 84058, USA. Email: colvinja @uvu.edu 
succeed in their program of study (e.g., Asbee \& Woodall, 2000; Cross, 1998; Goodlad, 1998; Hughes \& Fahy, 2009). Scholars such as Astin, Alexander, Wogelgesang, Ikeda, and Yee (2000) have studied the importance of fellow students interacting and encouraging other students to become involved on their campus. They suggest that academic involvement and interaction with faculty and fellow students increases the time and physical and psychological energy that students devote to the academic experience.

Two of the most common situations that involve students helping other students are peer tutoring and peer mentoring. Supplemental instruction, or what is more commonly called simply peer tutoring, typically focuses on a more advanced student helping lower-level students with course content. Peer mentoring focuses on a more experienced student helping a less experienced student improve overall academic performance, encourages mentors' personal growth (Falchikov, 2001; Kram, 1985), and provides advice, support, and knowledge to the mentee (University of South Australia, 2003).

However, as new subject positions - either peer tutors or peer mentors - are added to a classroom, new expectations are also added and challenged. In her study of university peer tutoring situations, Colvin (2007b) found that administrators cannot automatically assume that using tutors is without resistance from any or all of the parties involved - teachers, tutors, and students - and that clarification of roles is thus essential. She notes that using peer tutors requires a whole system of training and support concerning the socialization of students, teachers, and instructors.

In work on peer mentors, Reid (2008) claims the exact nature of expectations and boundaries is a crucial element in supporting peer mentors and the relationship between mentor and mentee. Storrs, Putsche, and Taylor (2008) additionally suggest that in order for mentoring relationships to be successful, there must be clarity and consensus of roles. If mentors and mentees do not have a clear sense of their roles and responsibilities, mentors will find it difficult to maintain any sort of self-efficacy (Hall, Draper, Smith, \& Bullough, 2008).

Colvin's (2007b) research focusing on peer tutors suggests that instructors, students, and even tutors themselves often do not understand the tutoring role, and sometimes even resist tutors. This article, an extension of Colvin's study, is an analysis of peer mentors, their interaction with students and instructors, the relationships that develop, and understanding the role of peer mentors in and out of the classroom.

\section{Mentoring Context}

The mentor program under study, at a large public university in the western United States, was created in 1990 as a mentor leadership program under the premise of students helping students. It primarily recruits students from the first year experience class (CLSS 1000) specifically to become mentors for that same class. Interested students take a mentoring leadership class (CLSS 2200) where they learn the theory of peer mentoring, including understanding the roles of a mentor, developing cultural sensitivity, enhancing communication skills, developing and maintaining relationships, managing time, and facilitating learning.

The second mentoring class, Mentoring Leadership II (CLSS 2300), is where students who have been newly selected as mentors apply mentoring leadership skills they learned in Mentoring Leadership I by mentoring the CLSS 1000 students. The third class in the program is Mentoring Leadership Practicum (CLSS 240R). Mentors 
enroll in this course each semester they serve in the program and practice facilitating learning in the classroom and share best practices. Throughout the semester, mentors also plan and attend monthly team-building activities.

Before each semester begins, mentors are paired with a faculty member in the department of college success studies, and each CLSS 1000 class is assigned a faculty member and a mentor. Training meetings precede each course so mentors and faculty members can meet and set goals for the semester. Mentors attend each class and work with students on both a class and individual basis. Mentors and faculty members continue to meet weekly, and training sessions take place periodically throughout the semester.

With the concerted efforts of training peer mentors in academic classes and staying true to the mission of students helping students, more than 400 students have served as mentors, affecting more than 15,000 students. Given these large numbers, it is important to understand the dynamics within these relationships.

\section{Method}

Data collection started in spring 2008 after obtaining Institutional Review Board approval and continued through spring 2009. Returning and new mentors, as well as instructors of and students in the university success studies class, were interviewed within this time period. In order to increase validity, data, investigator, and interdisciplinary triangulation were used. Data triangulation occurred through the use of observations, weekly reflection journals, and interviews. Investigator triangulation employed three different investigators; one approached the study with a focus on communication while the other two came from a background in working with firstyear students. The primary author had no prior experience working with the mentors, and the second author was an administrator and instructor in the mentor program. The other investigator, not an author of this articler, contributed her insight to data analysis as well. These different foci enabled interdisciplinary triangulation.

\section{Observation}

As researchers, we engaged in participant observation throughout the entire study and collected extensive field notes. Using this method, we spent time with the participants, joined in routine activities, and informally observed and recorded (Spradley, 1980). Observations were collected at all mentor activities, weekly classes and meetings, and other interactions in both formal and informal settings. Mentors were also assigned weekly reflections of their roles and responsibilities. The following excerpt is an example of the types of self-reflection that occurred:

I found [the weekly reflection assignment on roles and responsibilities] to be a very good activity to think about the different ways I can improve as a mentor and as a person this semester... I just want to be able to share my feelings about what is happening in this program more often in class.... I hope I can be a positive influence to the program and share my thoughts and ideas in a positive way. (Journal 3, Week 2)

Since diverse sources and data are crucial for qualitative research aimed at theory development (Glaser \& Strauss, 1967), additional data were gathered through interviews. 


\section{Interviews}

Interviews were conducted by the primary author with 12 current mentors, eight newly selected mentors, 10 instructors of the university success studies class, and 10 students in the class. Interviews ranged from 10 to 30 minutes, with the majority lasting 15 to 20 minutes. Questions were chosen to increase understanding about relationships and overall experiences in the program.

\section{Data Analysis}

Using a grounded theory approach (Glaser, 1978; Glaser \& Strauss, 1967), we inferred meanings as themes emerged from the data in response to the constituent group's perceived needs rather than preconceptions or frameworks from the researchers (Smythe \& Nicolai, 2002). By using such a qualitative approach, we sought to focus on mentors and how they used a set of discursive practices to locate themselves within the mentor program.

\section{Coding}

Coding took place in various stages. The primary author blind-coded all 40 interview transcripts, removing all identifying information. Periodically over the course of data analysis, transcripts were subjected to subsequent blind coding and review by the other authors. Using NVivo, a qualitative software analysis program, each interview was coded for attributes that were consistent across all interviews. Attributes included gender, role in program, years in program, definition of mentor, risks and benefits for mentors, students, and instructors as well as overall impressions. Attributes allowed us to qualitatively compare text. For example, we could see how many males in the program for two years felt that time management was a risk for mentors.

As attribute coding continued, the primary author also began coding for themes and dimensions. Only one of us did this type of coding so that interrater reliability was not an issue. As activities and interactions were observed, raw data was examined using a line-by-line analysis, and categories were labeled with properties and dimensions, such as role understanding and risks (Glaser \& Strauss, 1967). Next, patterns were noted. As repeated comments such as "I love helping people" occurred, they were grouped together under a "helping" label. This continued until categories became redundant. Ultimately, the primary categories included risks and benefits (for peer mentors, instructors, and students), definition of roles, and overall impressions. Field notes and reflection journals were used to double check and verify categories.

\section{Research Questions}

After initial coding, three research questions, each of equal importance, were developed:

(1) How do peer mentors, instructors, and students understand the peer mentor role?

(2) What types of power and resistance occur (if any) in these peer mentor relationships? 
(3) What is the response of the peer mentors, students, and instructors to the experience of mentoring?

Finally, categories were developed after discussion between the two researchers, review of the data, and integration between the categories with the aim of finding overall themes and discovering the relationship between them. Throughout the coding process, the primary author met with the other author to correlate the analysis. Using a grounded theory approach allowed us to uncover discrepancies, find patterns, and build theoretical concepts, rather than examining the data with a particular theoretical perspective.

\section{Results}

Findings indicate three areas of particular importance for mentoring: roles, benefits and risks, and power and resistance.

\section{Roles}

There were a total of 96 comments from students, mentors, and instructors about roles and their implications for mentors. Five specific roles were identified: connecting link, peer leader, learning coach, student advocate, and trusted friend.

Connecting link. A connecting link is a student that helps other students inside and outside of class get involved with their campus and education (Sanft Jensen \& McMurray, 2008). Nineteen of the 96 comments on the role of the mentor related to the role of connecting link, the majority of which focused on the mentor helping the students feel comfortable on campus and knowing the resources on campus. A student described such a situation:

I think it's really important for students to have mentors because it helps them to feel more comfortable in school.... Their role is to help students and to help them feel more comfortable, and I think they do that very well already, but I think that's kind of the main reason. (Interview 40)

Almost half of the 19 comments referred to the mentors' knowledge of resources and events on campus. Students viewed the mentor as someone who could help them become involved on campus - someone who knew more about available options and opportunities:

A peer mentor is someone who [is] an experienced student who can...inform [students] about resources on campus and events [that] are going on and just kind of be..... go-to-person for help in getting to know the campus better and just being informed on what resources are available. (Interview 40)

Peer leader. Only 10 of the 96 comments directly referred to mentors as peer leaders. However, many more referred to leadership qualities or how mentors motivate and guide their mentees. One student was inspired to become a peer mentor himself. He was "kind of jealous [and] wanted to be involved....and wanted to be a hard 
worker too" (Interview 40). Peer mentors encourage their students to get involved on campus, study more efficiently, and improve academically. Peer mentors often demonstrate leadership skills they are learning in the role of peer leader: "They're not just leaders to the students [in their class], they're leaders to all students... they're an example to all students" (Interview 40).

Learning coach. A learning coach helps students identify learning strengths and styles and achieve their potential (Sanft et al., 2008). This role received the most comments overall: 29 out of 96 . There were 13 references within the 29 comments that referred to peer mentors in the role of learning coach helping students want to persist through graduation and do better not just in the CLSS 1000 class but in all of their courses in college. Mentors make "one on one contact with another student giving encouragement to move ahead with a degree and succeed in classes" (Interview 26). One student shared a personal experience:

I think [mentoring] should play a part in [the institutions] recruiting and retention, people staying in school and actually graduation. I think it's a great draw to come to the program, come to the school because of the program but then also keep people in school. So I think from the university's standpoint it helps people stay in school and graduate. That's kind of what it's done for me. I never intended to graduate, and I am. (Interview 34)

In the role of learning coach, peer mentors teach students important academic and life skills (9 of 29). Some of these skills or strategies included "helping students on ways to improve their education, their study habits" (Interview 40) and being a "real help in the class" (Interview 39). One student shared a relevant example:

Last week we had a study group with our mentor, and she went over the test and any questions we had, and I thought that was really good because she took her time to meet with students for the class, to help us prepare for the exam. Not a lot of instructors have time to actually do that with their students. So mentors, they're kind of there to help us. So I thought that was really nice-just to go if we had questions, or if we kind-of were confused with what was asked, she was there to help. (Interview 37)

Peer mentors also helped with life skills (7 of 29), as shown in the following comment from a peer mentor:

I have a student who took way too many credits than what she was prepared for in her first semester and ended up being very overwhelmed and didn't know what to do.... Just by going over her syllabus with her, and different requirements, we were able to get her organized and catch up on all of her assignments. (Interview 36)

Student advocate. The role of student advocate was the second highest in comments, with 24 out of 96 . Twelve of the 24 comments related to the peer mentor being a helper, mostly in being a liaison between the student and the instructor. Many of the comments (four of 12) addressed the issue that students don't "feel like they can go to the instructor, [but] they can turn to the peer" (Interview 37). Instructors feel the same way: "By listen[ing] to [the mentor] we can see how the students perceive things" (Interview 24). 
Our research also showed that six of the 24 comments on the role of student advocate referred to helping the students with their academic and personal needs. One student shared that some personal struggles had been going on at home and the peer mentor was there for her both academically and personally:

This semester, I had a family crisis. It was a religious situation, and I was able to email my teachers and my mentor to kind of let her know what was going on, and both of them were extremely helpful... My mentor is actually in two of my other classes, and she was like: "Do you want me to take notes for you? I can help you out; I can let you know what's going on." She was just there. I mean, even after the class she just sat and talked with me about it, and she would help me out with anything. It was just really relieving to know that that person cared about me and where I was.... I trusted her enough to talk to her. (Interview 40)

The last of the five roles is trusted friend.

Trusted friend. Ten of the 96 comments referenced mentors being a trusted friend. One mentor shared that:

...a student was having a really hard time. [She] had a family member pass away, and that's when it went to the higher level of actually helping [her] with the right resources on campus and being a trusted friend and not just the mentor that was sitting in the class not really doing anything. So, the student came to me outside of class and really wanted my help, and that was a really good experience for both of us. (Interview 14)

These five roles of a peer mentor help to show how students, instructors, and mentors define the role of peer mentor.

\section{Benefits and Risks}

When asked about the experience of mentoring/being mentored, students, instructors, and mentors felt that there were both benefits and risks.

\section{Benefits}

Almost every proponent of peer approaches indicates some sort of benefit to both sides of a peer mentor relationship. Data from this study concur. When asked, "What benefit do you see for being a mentor?" there were three main themes: being able to support students, reapplying concepts in their own lives, and developing connections themselves.

Thirty-nine out of 77 comments focused on being able to support, help out, or uplift students. Mentors noted such things as: "[Mentoring] is just a great service opportunity to help others and kind of a selfish reason-I like doing it just to help other people" (Interview 9). Mentors also liked being able to help others be successful:

I had a student who was an immigrant from Mexico, and his father was supporting the family. He was living here with his mom, his father, and his sister, and his father died of a heart attack while working. And the mother, because [the father] could no longer support them and [the student] was in school, the mother 
had to move back to Mexico. The sister took a job in Disneyworld in Orlando, and he was left living here alone and ended up living with friends. That happened the second week of the semester, and I didn't see him for a couple of weeks. After a ton of phone calls and emails I got a hold of him and got him back in class and at least got him to pass the student success class. Whether or not he stayed and passed his other classes I don't know, but he at least passed our class. Those are the kind of experiences that probably sum up the biggest benefits for me is being able to help people who need and want help. (Interview 4)

Mentors also indicated that another benefit (22 out of 77) was involvement with others in the program and developing friendships. Comments included: "I think that it's such a good support system. You have the other mentors as a support system, and you are continually growing and learning" (Interview 2).

Interestingly, when comments about benefits are broken down by gender, the majority of women's comments (38 of 51) focused on relationships, and the majority of men's (20 of 26) noted improved grades and overall academic performance, not just for the students they worked with but also for themselves.

Finally, mentors also felt, as Goodlad (1998) suggested, that mentoring allowed them to reapply concepts into their own lives and helped them become even better students themselves:

There are principles that are taught in the class and by me mentoring. I am able to continually be refreshed on all those items, and I'm always able to... It is not uncommon for me to be doing, like teaching a presentation or preparing a presentation that I'm going to be giving to a class and realize that in my own schooling I need to reapply that. I've done it in the past, I know about it, but it reminds me. (Interview 1)

Sixteen of the 77 responses about benefits to peer mentors fell into the category of reapplication. Interestingly enough, although peer mentors each receive a full tuition scholarship for mentoring for two semesters, only three of the 77 responses mentioned this as a benefit.

While peer mentors viewed being able to mentor as a benefit to themselves as mentors, students also considered having mentors beneficial in helping with their class work and connecting them to campus. Fifty out of 137 comments focused on campus connections, including:

My mentor actually was extremely helpful with me, and not necessarily in the information I was learning in the class, but just connecting me to the campus, and helping me figure out financial aid and residency. I mean, there's so many aspects of college you don't know about when you're new, and your mentor just helps you see how to get through all of it. (Interview 28)

Others focused on retention benefits. "You're a lot more likely, if you learn how to be involved, to stay in school" (Interview 20).

The next most often expressed benefit for students was individual attention. Fortyfour of the 77 comments centered on having a friend or someone to help them one on one: “They're a mentor, they're there to help, and offer advice, just to be there for you. I know with having my mentor, I could ask her about anything, and she'd be willing to help me" (Interview 37). 
Almost equal to the number of responses about the benefit of individual help was the help mentors gave in class (43 out of 77). These responses focused on how mentors helped students succeed in their student success class. One peer mentor recalled:

A girl came in late, and I was asking if everything was okay and if she needed help, and I sat down to help her, and she was so relieved of the help. The student thought she was going to fail. [She said,] "I was going to fail but then you talked me out of it." She [had] thought all was lost. (Interview 27)

While there were very few comments about benefits for instructors having a peer mentor in their class, the main one mentioned was that instructors are able to receive feedback about the class that they might not normally receive from students.

However, while benefits were mentioned often, risks were also revealed.

\section{Risks}

Instructors, peer mentors, and students all saw some risk or challenge in maintaining a peer mentor relationship. Comments from mentors focused on their personal lives, interactions with students, and interactions with the instructors. Thirty-eight of the 70 comments in this category involved balancing both the specific requirements and personal desire to do well as mentors with time and other commitments: "I would say the biggest risk of being a mentor is people who are trying to do too much and people who are trying to be perfect in everything, and I think some of the times they can suffer from anxiety" (Interview 1).

Several mentors also expressed the idea that in becoming a mentor, they had to make themselves vulnerable, put themselves "out there" and risk rejection if students didn't accept them. This also involved getting very emotionally attached to students and then having to "let go" at the end of the semester.

Others saw risks and challenges in interacting with students (28 out of 70). These centered on students either being too dependent on the mentor or, conversely, not accepting the mentor. Students who were dependent were seen as needing a babysitter:

I think that I had a student this past semester actually that seemed a little too dependent on me for turning in his homework, or you know, not looking at his syllabus and stuff like that, so I think that dependency issues can come into play. (Interview 8)

This was a common theme: "There is a huge risk of depending on that person too much, using them as a crutch.... They're there to help, but they're not there to hold your hand through everything" (Interview 11). Still others perceived a possible physical risk for the mentors: "If they got upset with [the mentor] and sought revenge that could be dangerous" (Interview 28).

Additionally, students who did not accept mentors created challenges for the mentors who were supposed to be helping and working with them. One mentor indicated: "I took my time to devote to [the student], to work with him, and when I'd meet with him the next time he would not have done anything more than what we'd done together" (Interview 1).

Students saw risks and challenges in working with a peer mentor through two aspects: the role the mentor was fulfilling and the relationship that occurred. When 
focusing on the role, students, like mentors, saw themselves (or other students) as being too dependent on mentors.

Another student indicated that it was also a challenge if the mentor bothered them too much.

In addition, students were concerned about mentors failing to fulfill their role; for example: "if the mentor says they're going to be somewhere and they don't [show up]" (Interview 13). Several others expressed concern that if a peer mentor wasn't dedicated or didn't befriend the student, the student would suffer.

Relationships were seen as another risk for students. One remarked: "Sometimes it's hard for students to open up" (Interview 13). Another commented: "For those that are may be more shy, they have to get out of their bubble to let someone help them" (Interview 7). Several also expressed concern about favoritism. However, despite the risks and challenges described above, the most common response to this question in the interview was that there were no risks for students.

Out of only eight responses to the question about risks or challenges for instructors using mentors in their classroom, the most common (three) was figuring out how to interact with the mentor. When questioned further, one instructor indicated that it "takes time for the instructor to meet with the mentor and develop a relationship-it is easier to just do it myself" (Interview 16). One instructor was also uneasy about the possibility of having students go to mentors instead of to instructors: "If the [mentorstudent] relationship gets too comfortable, students call the mentor and tell them 'I'm not taking the test' and just [use] the mentor when they should be coming to the instructor" (Interview 18).

\section{Power and Resistance}

There were a number of types of resistance that occurred. Instructors were resistant when they expressed that the relationship with mentors took too much time. Students also expressed resistance when they indicated that sometimes mentors pestered them too much when they didn't need help. However, the majority of concern about resistance came from mentors as they talked about trying to fulfill their role. This list of comments suggested resistance (the numbers indicate specific instances of that type):

(1) Students not doing assignments (two)

(2) Instructor won't let the mentor do their job (one)

(3) Students don't want to open up to the mentor (one)

(4) Relationship clashes (two)

(5) Communicating with students (one)

(6) Students don't want help (three)

(7) Being out on their own in class (too little instructor support) (one)

Overall, risks, power, and resistance were acknowledged but benefits were recognized much more frequently by all participants.

\section{Discussion}

Other researchers have studied peer mentor characteristics (see Terrion \& Leonard, 2007), but few identify the types of mentor roles recognized by mentors, students, and instructors, with the exception of Sanft and colleagues (2008). In this study, we found that peer mentors identify with five roles of a peer mentor: connecting link, 
peer leader, learning coach, student advocate, and trusted friend. Supporting Smith's (2008) findings, we show that these roles require not only identification but also careful planning and adjustment. While the fact that mentors fulfill particular roles may be fairly obvious, many times the fact that those roles come with benefits and risks is not.

In general, both peer mentors and students saw benefits, ranging from individual gains to helping students become connected to the campus as a whole. When responses were examined along gender lines, women focused on the benefits of having a friend and a support system (i.e., relationship-centered responses). Men, on the other hand, indicated that the biggest benefit was that they learned more because they had help from an equal or peer (i.e., content-centered responses).

Students and mentors agreed that one of the major benefits of having (or being) a mentor was doing better in school. Thomas's (2000) study of student retention supports this as well. He found that students perform better academically and are more likely to persist in school when "those students who possess broader, well-connected networks... are able to more easily make connections with others due to the multitude of paths reaching to many parts of the overall network" (pp. 601-602).

However, though there were many benefits, risks and challenges were also apparent. Much of these may stem from the overall infrequent use of mentors in classrooms and students' (as well as instructors') unfamiliarity with the process and relationship. In addition, "questions of expertise, experience, and power can complicate what appears to be straightforward expert-novice interaction" (Smith, 2007, p. 88). In her research using peer mentors to help students develop transferable life skills, Dunne (2000) suggests that "one of the problems of introducing new processes of learning is that it tends to be difficult for both those that provide them and for those who should gain from them" (p. 369). Bruffee (1994) has also identified problems with collaborative learning:

Willingness to grant authority, willingness to take on and exercise authority, and a context of friendliness and good grace are the three ingredients essential to successful autonomous collaboration. If any of these three is missing or flags, collaboration fails. These three ingredients are essential also to successful semiautonomous collaboration, such as classroom collaborative learning. (p. 44)

Additionally, the nature of the relationship, mentor and mentee, reflects hierarchical ordering. Thus help, power, and resources tend to flow in one direction, creating the possibility for misunderstanding or misuse of such power and resources and leading to challenges and resistance.

Interestingly enough, some light can be shed on risks and challenges for mentors through comparison with the amount of time mentors had been participating in the program. Those who were first- and second-year mentors saw the students' overdependence as the major risk. By the third year, mentors focused mainly on time management as the major risk. These comments may reflect the predominant culture of higher education, in which the teacher is the one who has the right to question, command, challenge, and occupy the talking space in a classroom. Having to share that space with a mentor challenges even those who want to move away from a less collaborative mindset in the classroom.

Colvin (2007a) found that peer tutors cannot automatically expect peer interactions in classrooms to be met with open arms by everyone involved. Students waited 
to assign positional power to tutors until the latter helped students in ways in which the students wanted to be helped. If this did not happen, students disregarded tutors. In her study of composition mentors and mentees, Reid (2008) notes: “one's mentor may seem too unlike oneself, too unlikable, or too unreliable to make the mentoring experience enjoyable or even worthwhile" (p. 70). Peer mentors were thus met with issues of power and resistance, many of which are manifest in data about risks and benefits.

Issues of power in this study were not blatant but rather couched in terms of mentors feeling powerful because they were helping students succeed rather than because they felt the role itself was imbued with inherent power. Several students voiced the concern that mentors could abuse the relationship or not fulfill their role. Again, this was a more subtle form of issuing power: recognition that the mentors have the ability to do either of these things rather than an outright statement of the mentor having power. Students also had power: power to accept or reject a mentor's help.

These findings extend Colvin's (2007b) study in suggesting that in more established programs, such as the one at this institution, peer mentor relationships still encounter power and resistance issues to a smaller degree, but they are recognized more as risks and benefits. Successful peer mentoring, just like, and perhaps even more so than peer tutoring, is the result of relationships among students, mentors, and instructors: it does not happen in a vacuum.

Findings from this study indicate that even in programs such as this university's student success program, where training is ongoing and established, assumptions cannot be made about the understanding of roles, risks and benefits, and how those risks and benefits translate into issues of power and resistance. Students, teachers, and mentors all have different ideas about a mentor's role and how it should be enacted in various relationships. More clarification for all parties could help establish the role more clearly and alleviate confusion. This could be especially true if mentor programs focus on particular roles rather than all five. Clarification of instructor and student roles, particularly in a first-year experience class, would also be helpful.

Finally, this study extends Colvin's (2007a) study with peer tutors in communication classes by utilizing peer mentors in the first-year student success program. It demonstrates that despite differences in role definitions, peer mentors, as well as peer tutors, need to clarify roles, understand expectations of all parties, and receive training on developing, maintaining, and managing relationships. As Reid (2008) suggests: "real magic in a mentoring program comes in attention to details, in attentiveness and planning, in learning and practicing and reflecting" (p. 71).

\section{Conclusion}

From this research, it becomes apparent that two components not addressed in Colvin's (2007a) study offer interesting avenues for future research. First, the amount of time in the program can affect responses. Peer mentors who have been in the program longer seem able to deal with relationship issues easier than novice mentors. Second, gender makes a difference. Responses indicate that women see relationship benefits and men see academic benefits. Future research needs to develop these findings further to see if experience and gender make a difference in more substantial ways, such as how mentor roles are enacted and how that changes the experience of those involved. Future research should also focus on the affect of relationship training on the mentor experience. 
This study, conducted at a large western US university, may reflect a western bias. However, other peer mentoring studies conducted outside of the western United States note some similarities. In Smith's (2008) study of peer mentors at the University of Calgary, she emphasized that careful planning and adjustment is needed before integrating peer mentors into courses. Similarly, though not academically focused, Cunningham (2007), in mentoring trainee teachers in the United Kingdom, and Mills, Lennon, and Francis (2007), in mentoring and training Australian rural nurses, found that clarity and consistency of job description and role can help ensure that mentors are successful.

This study may be worth consideration by other programs outside North America to assess whether these roles and recognition of benefits and resistance hold true to programs with contexts different from this particular study. Such assessment would provide comparative data that would extend our understanding of the peer mentoring position in higher education.

\section{Notes on the Contributor}

Janet Colvin, Assistant Professor, Communication Department at Utah Valley University for the past 4 years. She serves as adjunct coordinator and speech communication emphasis coordinator. She received her undergraduate degree in Organizational Communication from Brigham Young University, and masters and doctorate in Speech Communication from University of Utah.

Marinda Ashman, Assistant Professor, Department of College Success Studies at Utah Valley University for the past 4 years. Serves as Director of the Student Success and UV Mentor Program. Works daily with UV Mentors in the classroom, with mentors holding leadership positions, and oversees the training and direction of the UV Mentor Program. Received her undergraduate degree in Elementary Education from Brigham Young University, graduate degree in Education from Utah State University.

\section{References}

Asbee, S., \& Woodall, S. (2000). Supporting access in distance education through studentstudent mentoring. Journal of Access and Credit Studies, 2(2), 220-232.

Astin, A.W., Alexander, W., Wogelgesang, L.J., Ikeda, E.K., \& Yee, J.A. (2000). How service learning affects students. Los Angeles: Higher Education Research Institute, University of California at Los Angeles.

Bierema, L., \& Merriam, S. (2002). E-mentoring: Using computer-mediated communication to enhance the mentoring process. Innovative Higher Education, 26(3), 211-227.

Bruffee, K.A. (1994). Making the most of knowledgeable peers. Change, 26(3), 39-45.

Campbell, T.A., \& Campbell, D.E. (1997). Faculty/student mentor program: Effects on academic performance and retention. Research in Higher Education, 38(6), 727-742.

Colvin, J.W. (2007a). Peer tutoring and social dynamics in higher education. Mentoring \& Tutoring: Partnership in Learning, 15(2), 165-181.

Colvin, J.W. (2007b). Peer tutoring and the social dynamics of a classroom. Saarbrucken, Ger: VDM Verlag Publishing Company.

Cross, S. (1998). Roots and wings: Mentoring. Innovations in Education and Training International, 36(3), 224-230.

Cunningham, B. (2007). All the right features: Towards an "architecture" for mentoring trainee teachers in UK further education colleges. Journal of Education for Teaching, 33(1), 83-97.

Dunne, E. (2000). Bridging the gap between industry and higher education: Training academics to promote student teamwork. Innovations in Education and Training International, $37(4), 361-371$. 
Dyrli, O.E., \& Kinnaman, D.E. (1995). Connecting classrooms: School is more than a placeWhat every teacher needs to know about technology. Technology and Learning, 10(8), $82-88$.

Falchikov, N. (2001). Learning together: Peer tutoring in higher education. New York: RoutledgeFarmer.

Glaser, B.G. (1978). Theoretical sensitivity. Mill Valley, CA: Sociology Press.

Glaser, B.G., \& Strauss, A.L. (1967). The discovery of grounded theory: Strategies for qualitative research. Chicago: Aldine.

Goodlad, S. (1998). Mentoring and tutoring by students. London: BP Educational Service.

Grant-Vallone, E.J., \& Ensher, E.A. (2000). Effects of peer mentoring on types of mentor support, program satisfactions and graduate student stress: A dyadic perspective. Journal of College Student Development, 4(16), 637-642.

Hall, K.M., Draper, R.J., Smith, L.K., \& Bullough, R.V. (2008). More than a place to teach: Exploring the perceptions of the roles and responsibilities of mentor teachers. Mentoring \& Tutoring: Partnership in Learning, 16(3), 328-345.

Hughes, A., \& Fahy, B. (2009). Implementing an undergraduate psychology mentoring program. North American Journal of Psychology, 11(3), 463-469.

Kazmer, M. (2004). Online identity: Implications for course design. Online classroom, January, 6-8.

Kram, K.E. (1985). Mentoring at work. Glenview, IL: Scott, Foresman.

LaFee, S. (2003). Professional learning communities. School Administrator, 60(5), 6-13.

Materniak, G. (1984). Student paraprofessionals in the learning skills center. In S.C. Ender \& J.R.B. Winston (Eds.), Students as paraprofessional staff (23-36). San Francisco: Jossey-Bass.

Miller, J.E., Groccia, J.E., \& Miller, M.S.E. (2001). Student-assisted teaching: A guide to faculty-student teamwork. Bolton, MA: Anker.

Miller, R. (2000). Creating learning communities: Models, resources, and new ways of thinking about teaching and learning. Brandon, VT: Foundation for Educational Renewal.

Mills, J., Lennon, D., \& Francis, K. (2007). Contributing to a culture of learning: A mentor development and support project for Australian rural nurses. International Journal of Nursing Practice, 13(6), 393-396.

Reid, E.S. (2008). Mentoring peer mentors: Mentor education and support in the composition program. Composition Studies, 36(2), 51-79.

Sanft, M., Jensen, M., \& McMurray, E. (2008). Peer mentor companion. Boston, MA: Houghton Mifflin.

Smith, B.L. (1993). Creating learning communities. Liberal Education, 79(4), 32-36.

Smith, E.R. (2007). Negotiating power and pedagogy in student teaching: Expanding and shifting roles in expert-novice discourse. Mentoring \& Tutoring: Partnership in Learning, 15(1), 87-106.

Smith, T. (2008). Integrating undergraduate peer mentors into liberal arts courses: A pilot study. Innovative Higher Education, 33, 49-63.

Smythe, M., \& Nicolai, L.A. (2002). A thematic analysis of oral communication concerns with implications for curriculum design. Journal of Accounting Education, 20(3), 163-181.

Spradley, J.P. (1980). Participant observation. New York: Holt, Rinehart, and Winston.

Storrs, D., Putsche, L., \& Taylor, A. (2008). Mentoring expectations and realities: An analysis of metaphorical thinking among female undergraduate protégés and their mentors in a university mentoring programme. Mentoring \& Tutoring: Partnership in Learning, 16(2), $175-188$.

Terrion, J.L., \& Leonard, D. (2007). A taxonomy of the characteristics of student peer mentors in higher education: Findings from a literature review. Mentoring \& Tutoring: Partnership in Learning, 15(2), 149-164.

Thomas, S.L. (2000). Ties that bind. Journal of Higher Education, 71(5), 591-615.

University of South Australia (2003). Mentoring resource kit. Retrieved January 5, 2010, from http://www.unisa.edu.au/hrm/courses/mentoring_resource_kit_dec2003.doc 
Copyright of Mentoring \& Tutoring: Partnership in Learning is the property of Routledge and its content may not be copied or emailed to multiple sites or posted to a listserv without the copyright holder's express written permission. However, users may print, download, or email articles for individual use. 